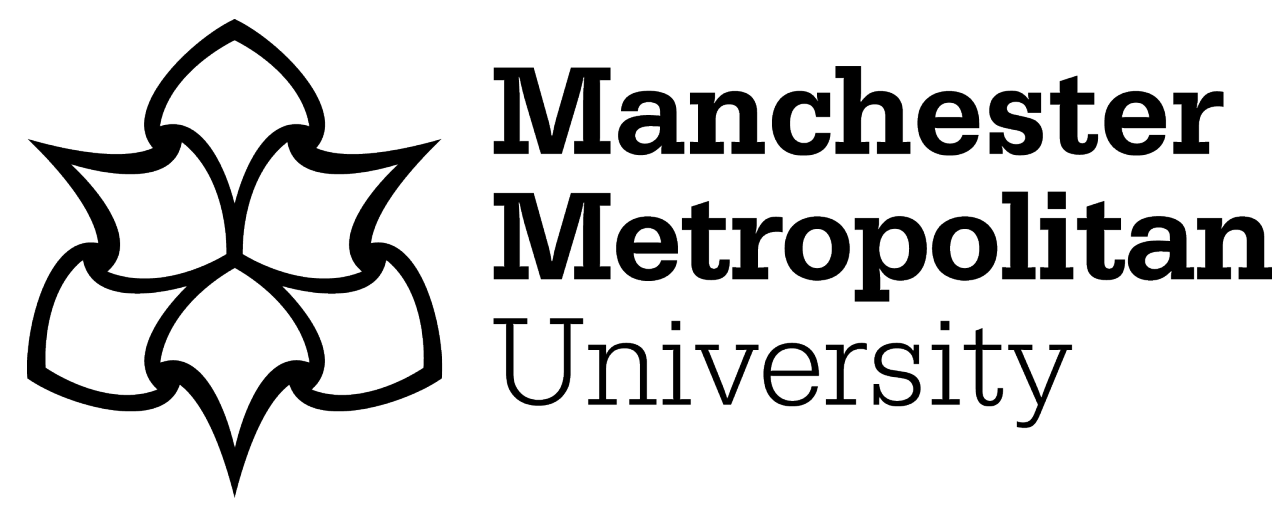

Garnett, ST, Burgess, ND, Fa, John, Fernández-Llamazares, A, Molnár, Z, Robinson, CJ, Watson, JEM, Zander, KK, Austin, B, Brondizio, ES, Collier, NF, Duncan, T, Ellis, E, Geyle, H, Jackson, MV, Jonas, H, Malmer, P, McGowan, B, Sivongxay, A and Leiper, I (2018) A spatial overview of the global importance of Indigenous lands for conservation. Nature Sustainability, 1. pp. 369-374. ISSN 2398-9629

Downloaded from: https://e-space.mmu.ac.uk/621204/

Publisher: Nature Research

DOI: https://doi.org/10.1038/s41893-018-0100-6

Please cite the published version 


\section{A spatial overview of the global importance of Indigenous lands for conservation}

Stephen T. Garnett ${ }^{1}$, Neil D. Burgess ${ }^{2,3}$, John E. Fa ${ }^{4,5}$, Álvaro FernándezLlamazares $^{6}$, Zsolt Molnár ${ }^{7}$, Cathy J. Robinson ${ }^{1,8}$, James E.M. Watson ${ }^{9,10}$, Kerstin K. Zander $^{1}$, Beau Austin ${ }^{1}$, Eduardo S. Brondizio ${ }^{11}$, Neil French Collier ${ }^{1}$, Tom Duncan ${ }^{1}$, Erle Ellis ${ }^{12}$, Hayley Geyle ${ }^{1}$, Micha V. Jackson ${ }^{1,13}$, Harry Jonas ${ }^{14}$, Pernilla Malmer ${ }^{15}$, Ben McGowan ${ }^{1}$, Amphone Sivongxay ${ }^{1} \&$ lan Leiper $^{1}$

${ }^{1}$ Charles Darwin University, Ellengowan Dr, Casuarina NT 0810, Australia

${ }^{2}$ UN Environment World Conservation Monitoring Centre (UNEP-WCMC), 219 Huntingdon Rd, Cambridge CB3 ODL, UK

${ }^{3}$ Center for Macroecology, Evolution and Climate, Natural History Museum of Denmark, Universitetsparken 15, Building 3, 2nd floor, DK-2100 Copenhagen, Denmark

${ }^{4}$ Division of Biology and Conservation Ecology, School of Science and the Environment, Manchester Metropolitan University, Manchester M1 5GD, UK ${ }^{5}$ Center for International Forestry Research (CIFOR), Jalan Cifor Rawajaha, Situ Gede, Bogor Barat, Kota Bogor, Jawa Barat 16115, Indonesia

${ }^{6}$ Helsinki Institute of Sustainability Studies (HELSUS), Faculty of Biological and Environmental Sciences, University of Helsinki, FI-00014 Helsinki, Finland

${ }^{7}$ Centre for Ecological Research, Hungarian Academy of Science, 2163 Vácrátót, Hungary

${ }^{8}$ CSIRO, Ecoscience Precinct, 41 Boggo Rd, Dutton Park QLD 4102, Australia

${ }^{9}$ School of Earth \& Environmental Sciences, The University of Queensland, 
Brisbane QLD 4072 Australia

${ }^{10}$ Wildlife Conservation Society, 2300 Southern Boulevard, Bronx, New York 10460, USA

${ }^{11}$ Department of Anthropology, Indiana University, 701 E. Kirkwood Ave, Student Building 130, Bloomington, IN 47405-7100, USA

${ }^{12}$ Geography \& Environmental Systems' University of Maryland, Baltimore, MD 21250, USA

${ }^{13}$ School of Biological Sciences, The University of Queensland, Brisbane QLD 4072 Australia

${ }^{14}$ Natural Justice, Mercantile Building, 63 Hout Street, Cape Town, 8000, South Africa

${ }^{15}$ Stockholm Resilience Centre, Stockholm University, Kräftriket 2B, SE-10691, Sweden 


\begin{abstract}
Understanding the scale, location and nature conservation values of the lands over which Indigenous Peoples exercise traditional rights is central to implementation of several global conservation and climate agreements. However, spatial information on Indigenous lands has never been aggregated globally. Here, using publicly available geospatial resources, we show that Indigenous Peoples manage or have tenure rights over at least $\sim 38$ million $\mathbf{k m}^{2}$ in 87 countries or politically distinct areas on all inhabited continents. This represents over a quarter of the world's land surface, and intersects about $40 \%$ of all terrestrial protected areas and ecologically intact landscapes (e.g. boreal and tropical primary forests, savannas and marshes). Our results add to growing evidence that recognizing Indigenous Peoples' rights to land, benefit sharing, and institutions is essential to meeting local and global conservation goals. The geospatial analysis presented here indicates that collaborative partnerships involving conservation practitioners, Indigenous Peoples and governments would yield significant benefits for conservation of ecologically valuable landscapes, ecosystems and genes for future generations.
\end{abstract}

\title{
Introduction
}

There are at least 370 million people who define themselves as Indigenous ${ }^{1}$, are descended from populations who inhabited a country before the time of conquest or colonisation, and who retain at least some of their own social, economic, cultural and political institutions ${ }^{2}$ (Supplementary Information 1). Irrespective of their global diversity, Indigenous Peoples often express deep spiritual and cultural ties to their land and contend that local ecosystems reflect millennia of their stewardship, with 
Indigenous Peoples' lands representing one of the oldest forms of conservation units $^{3,4}$. Moreover, they assert that Indigenous rights do not require state-sanctioned approval to exist ${ }^{5}$. While Indigenous Peoples' land rights are acknowledged and implemented to varying degrees across time and geography, even when refused or ignored, Indigenous Peoples frequently retain de facto influence over their ancestral lands. This is often regardless of state-imposed tenure ${ }^{6}$ and/or the pressures and conflicts that surround them. Important efforts exist nationally, regionally, and globally to recognize and map Indigenous lands ${ }^{7}$. Yet, global maps of Indigenous Peoples' land occupation or management are often contentious because they tend to rely on state-sanctioned data that can be deployed to disenfranchise Indigenous Peoples $^{8}$. The dearth of reliable data on Indigenous Peoples' lands in many parts of the world has implications not only for securing their rights but also for the conservation and management of a significant proportion of terrestrial global biodiversity ${ }^{4,9,10}$.

Increasingly sophisticated spatial tools are being developed to determine national responsibilities towards global environmental targets ${ }^{11}$. Yet, there is currently no comprehensive global assessment of the extent to which Indigenous Peoples' stewardship and global conservation values intersect. Existing datasets such as LandMark suggest that overlap is substantial ${ }^{12}$. In this paper, we provide a first estimation of the overlap between Indigenous Peoples' terrestrial lands and protected areas ${ }^{13}$, human anthropogenic biomes (anthromes) ${ }^{14}$ and the degree that humans influence these lands (for which we use the updated global Human Footprint $\left.{ }^{15}\right)$. These analyses allow us to understand the extent to which Indigenous Peoples are involved in managing areas of high conservation value (see Methods). 
Our results will contribute to global policy recognition of the conservation attributes of Indigenous Peoples' lands, including the Strategic Plan for Biodiversity 2011-202016 and its successor, the UN Sustainable Development Goals ${ }^{17,18}$ and to fulfil the aspirations of the Intergovernmental Science-Policy Platform on Biodiversity and Ecosystem Services (IPBES) ${ }^{19}$.

\section{Extent and conservation importance of Indigenous Peoples' lands}

We first created a global map of terrestrial lands managed or owned by Indigenous Peoples throughout the world (Fig. 1). This dataset is based on information compiled in 127 data sources, including cadastral records for State-recognised Indigenous Peoples' lands, publicly accessible participatory mapping, models based on census data and maps derived from scholarly publications. We identified Indigenous Peoples' lands in 87 of 235 countries or administratively independent entities, excluding Antarctica and uninhabited islands in the Southern Ocean (Extended Data Table 1). This encompassed areas where Indigenous Peoples' land tenure is officially recognised and where, according to our data sources, Indigenous Peoples retain a substantial de facto influence on land management. We define land management here as the process of determining the use, development and care of land resources in a manner that fulfils material and non-material cultural needs, including livelihood activities such as hunting and fishing, gathering, resource harvesting, pastoralism, subsistence and commercial agriculture and horticulture.

Fig. 1 around here 
Our results show that Indigenous Peoples have rights to and/or manage at least 37.9 million $\mathrm{km}^{2}$ of land in nearly all mainland countries in the Americas; around the Arctic; throughout most of the forested lands of south and Southeast Asia; across Africa particularly in rangelands and deserts but also forests; and throughout countries in Oceania, including many small island nations (Fig.1, Supplementary Table S1 and S2). The proportion of countries with Indigenous Peoples is highest in Africa and lowest in Europe-West Asia (Extended Data Table 2 and Table 3). In total, Indigenous Peoples influence land management across at least $28.1 \%$ of the land area.

About 7.8 million $\mathrm{km}^{2}$ (20.7\%) of Indigenous Peoples' lands are within protected areas, encompassing at least $40 \%$ of the global protected area (Supplementary Table S2, Extended Data Fig. 1) with the proportion of Indigenous land in protected areas significantly higher than the proportion of other lands that are protected (Fig.2, Extended Data Table 3). The relationship between Indigenous Peoples and conserved areas varies in nature. While some protected areas (as defined by states and/or IUCN) are under the governance of Indigenous Peoples themselves, others are governed by state authorities with varying degrees of respect for the presence of Indigenous Peoples. This respect ranges from collaborative governance where Indigenous peoples are consulted on decisions, to de facto management and use of protected areas by Indigenous Peoples despite threats of eviction. Our data do not provide information on either the legal relationship or the nature of the use made of protected areas by Indigenous Peoples. It does indicate, however, that the scale of spatial overlap positions Indigenous Peoples as important global actors in protected area management. The contributions of some Indigenous Peoples to national 
protected area coverage have sometimes been provided with free, prior and informed consent, as is the case with Indigenous Protected Areas that make up 45\% of the protected area network in Australia ${ }^{20}$. In many regions, however, protected areas have been imposed over Indigenous Peoples' lands without consent, sometimes leading to conflict, social disadvantage and displacement ${ }^{21}$.

\section{Fig. 2 around here}

Around half of the global terrestrial environment can be classified as human dominated $^{22}$. Using this as a measure of human influence, we estimated that Indigenous Peoples' lands account for $37 \%$ of all remaining natural ${ }^{23}$ lands across Earth (Extended Data Fig. 1, Extended Data Table 2). A higher proportion (67\%) of Indigenous Peoples' lands was classified as natural compared with $44 \%$ of other lands (Fig.2, Extended Data Table 3, Supplementary Table S2). While no global data are available on other anthropogenic pressures such as grazing, burning, hunting or fishing, the drivers assessed by the Human Footprint (which range from roads, access, population density and different agricultural land use activity) are suitable surrogates ${ }^{15}$. Consistent with this, most parts of the planet managed and/or owned by Indigenous Peoples have low-intensity land uses: less than 3.8 million $\mathrm{km}^{2}$ $(10.2 \%)$ of the world's urban areas, villages and non-remote croplands are on Indigenous Peoples' lands, while by contrast they encompass 24.9 million $\mathrm{km}^{2}$ $(65.7 \%)$ of the remotest and least inhabited anthromes (Fig.3, Fig. 4, Supplementary Data Table 3). Many of these remote Indigenous areas are nevertheless under pressure for intensive development ${ }^{24}$. 


\section{Figure 3 around here}

\section{Figure 4 around here}

\section{Consequences of Indigenous influence on land management}

The striking feature of our analysis is that although Indigenous Peoples' represent $<5 \%$ of the global population ${ }^{1}$, they currently manage or have rights over many of the world's most sparsely populated, intact places. Countless Indigenous management institutions have already proven to be remarkably persistent and resilient, suggesting that such governance forms can shape sustainable human-landscape relationships in many places ${ }^{25,26,27}$. This means that, even for localities where Indigenous Peoples are still in the process of regaining land rights, the maintenance of the conservation values of a significant share of the planet depend on the institutions and actions of Indigenous Peoples ${ }^{28}$. This analysis similarly highlights the pressing need to understand the interactions between Indigenous and environmental considerations as an essential back drop when negotiating local or global conservation agreements on and off Indigenous lands ${ }^{29,30}$. Nonetheless, Indigenous-conservation alliances should not assume that all Indigenous Peoples have a strong desire or willingness to maintain the natural environment in its current state ${ }^{31}$. This is because Indigenous Peoples have a wide range of legitimate political, cultural and economic aspirations for their lands and, as a result, conservation priorities and regulations often differ or even clash with Indigenous management ${ }^{32}$.

There is also the need to consider any implied expectation of asking Indigenous Peoples to take on the burden of our global conservation challenges without providing them with adequate resources and support. Conservation policies that aim 
to protect wilderness on Indigenous lands need to ensure that these policies not only deliver biodiversity returns but receive strong local support and align with Indigenous Peoples' motivations, governance, and capacities. This reinforces the importance of 'bottom-up' approaches to conservation investment and policy design, particularly given the limited success of 'top-down' Indigenous-conservation agreements to date ${ }^{3,33}$. There is a wide array of innovative approaches and tools to facilitate discussion of collaboration, co-management and power-sharing around conservation initiatives, for reasons of social justice and more inclusive environmental governance. These include sets of Indigenous-led codes of ethical conduct in conservation (e.g., Akwe: Kon Guidelines and The Tkarihwaié:ri Code of Ethical Conduct $^{34,35}$ ) and tools for dialogue such as the Whakatane Mechanism ${ }^{36}$, providing a collaborative framework that can ensure the full and effective involvement of Indigenous Peoples in conservation, while respecting their rights and institutions. The use of these policy support tools is particularly relevant for defining and negotiating resource sharing rights in different conservation contexts.

More importantly, the emphasis should be to recognise and support the contributions that Indigenous Peoples and local communities make to the conservation of biodiversity in the most appropriate way, not necessarily through protected areas. Some may be by the designation of protected areas after due process (including free, prior and informed consent) but it may also be through the recognition of 'other effective area-based conservation measures' (OECMs) such as proposed under the Aichi Biodiversity Target 11 of the Convention on Biological Diversity (CBD) $)^{37}$ or simply by working to support ongoing activities outside of any formal recognition or reporting requirements. Indigenous Peoples' lands are expected to constitute a 
substantial subset of the world's OECMs, in cases where conservation is not necessarily the primary objective but is nevertheless an outcome ${ }^{38}$.

Indeed Indigenous Peoples often manage their lands in ways that are compatible with, and often actively support, biodiversity conservation ${ }^{4}$. They can co-produce, sustain, and protect genetic, species and ecosystem diversity all over the world by 'accompanying' natural processes, for example creating cultural landscapes with high habitat heterogeneity ${ }^{39}$ and developing and restoring ecosystems with novel species combinations of wild and domesticated species ${ }^{40}$. Furthermore, Indigenousled approaches have highlighted innovative ways to design conservation reserves, environmental policy instruments, wildlife monitoring and management programs ${ }^{41,42,43}$. Approaches that take into account Indigenous peoples' unique ties with nature and their extensive local knowledge are providing pathways that reevaluate existing conservation frameworks ${ }^{44}$. As such, this will open up myriad opportunities for partnerships between conservation practitioners and Indigenous Peoples to create mutual benefits ${ }^{37}$.

Strengthening the Indigenous voice in land use decisions

We acknowledge that any global assessment of Indigenous Peoples' lands is potentially contentious (see Supplementary Information 2). Official definitions of Indigenous Peoples are often contested, as are legally sanctioned boundaries that delimit Indigenous Peoples' territories. Nonetheless, OECMs are likely to increase as overlaps between conservation areas and Indigenous Peoples' lands and interests are progressively identified. This will mean that we are further towards achieving 
some elements of Aichi Biodiversity Target 11 than is currently being reported; yet, the contributions of Indigenous Peoples to the management and monitoring of protected areas are rarely recognised in official statistics ${ }^{10}$.

We are also aware that self-identification as 'Indigenous' may not be plausible in some countries and that Indigenous Peoples' rights and land management practices vary greatly in extent, scope and influence ${ }^{38}$. Nonetheless, Indigenous Peoples increasingly choose to engage in global forums and debates about the state and future of the planet's environment, including through participation in global policyrelated processes such as IPBES and the CBD. This has led to participation of representatives of Indigenous Peoples in IPBES assessments, and will lead to the active engagement of representatives of Indigenous Peoples in development of the post-2020 global biodiversity framework that will replace the Strategic Plan for Biodiversity 2011-2020 when it comes to an end. These efforts need to sit alongside local, context-specific and Indigenous-led agreements on how the conservation of our planet's ecosystems can safeguard Indigenous Peoples' rights and futures ${ }^{28}$, and vice versa. There is already good evidence that recognition of the practices, institutions and rights of Indigenous Peoples in global environmental governance is essential if we are to develop and achieve the next generation of global biodiversity targets $^{16,18,37,38}$ 


\section{Methods}

Overview. To assess the role of Indigenous Peoples in the conservation of biodiversity across the world, we used five spatial datasets: (1) administrative areas; (2) geographical extent of Indigenous Peoples' lands; (3) protected areas; (4) the Human Footprint; and (5) anthromes. For each country or administratively independent entity, we intersected these datasets to calculate the area of Indigenous Peoples' lands, protected areas, natural lands, and low and high intensity anthromes. Geospatial analyses were conducted in the Mollweide projection using ArcGIS v10.4.1 and ArcGIS Pro v1.3.

Administrative areas. Geospatial data for the world's administrative areas were sourced from the Global Administrative Areas (GADM) spatial database ${ }^{47}$. Administration areas were dissolved according to ISO3 and Name_0 attributes for geoprocessing at a country or administratively independent entity level. For presentation purposes, administration areas were later grouped into four regions following the IPBES regionalization ${ }^{48}$. The following areas were consolidated in our analyses: Aland Islands and Finland; China, Macao and Hong Kong; Australia, Christmas, Norfolk and Cocos Keeling Islands; Cyprus, Akrotiri and Dhekelia; USA Minor Outlying Islands and, although a French Territory, Clipperton Island; United Kingdom, Guernsey, Jersey and Isle of Man.

Indigenous Peoples' lands. We used the International Labour Organization's definition of Indigenous Peoples ${ }^{2}$ (Supplementary Information 1). The geographical extent of Indigenous lands was sourced or delineated based on open-access published sources (Extended Data Table 1). In selecting these information sources, priority was given to peer-reviewed literature, books by academic publishers, and 
reputable data providers such as documented on the LandMark Global Platform of Indigenous and Community Lands ${ }^{12}$.

Protected areas. We used the World Database on Protected Areas (WDPA) ${ }^{13}$ to determine the extent of mostly state-managed protected areas, but also a fairly good sample of community managed reserves and some private reserves. Data were provided with the following filters applied: removal of protected areas with a designation of UNESCO MAB Biosphere Reserves because they may include large areas that do not meet the IUCN definition of protected areas; removal of areas with a status of "not reported" or "proposed"; creation of circular buffers around point data based on reported areas and removal of point data with no reported area. We further deleted areas designated as $100 \%$ marine protected areas (attribute MARINE=2) because our study focused on terrestrial areas. Protected areas on Reunion, attributed to France, and American Samoa, attributed to the United States of America, were reclassified to the islands on which they occur.

The WDPA database contained overlapping protected areas with different IUCN management categories and different ISO3 codes. To account for this and to create a flat WDPA layer for each administrative area, all protected areas with a particular ISO3 code were selected and clipped to the extent of the relative GADM administration area. Where protected areas overlapped, a single IUCN management category was assigned according to the following hierarchy: la, Ib, II, III, IV, V, VI, Not Assigned, Not Reported, Not Applicable. Creating a flat layer using this method avoided inflated protected area coverage values and excluded protected areas from neighboring countries that nominally extend beyond their jurisdiction. 
Human Footprint. Human Footprint data are a standardized measure of cumulative human pressures on the environment that take into account the extent of built environments, crop land, pasture land, human population density, night-time lights, railways, roads and navigable waterways ${ }^{15}$. The Human Footprint ranges between values of 0 and 50 , calculated at a $1 \mathrm{~km}^{2}$ resolution across the Earth's terrestrial surface. Land can be considered human-dominated rather than "natural" using a Human Footprint value threshold of 4 or greater ${ }^{22}$; a value of 0 is equivalent to no detectable human pressures of the type incorporated in the Index. Human Footprint maps for 1993 and 2009 were downloaded from the Dryad Digital ${ }^{49}$. It has been used to measure and classify habitat degradation ${ }^{22}$, connectivity for species ${ }^{50}$, global wilderness decline ${ }^{23}$ and the extent of human influence on protected areas ${ }^{51}$ Anthromes. Anthropogenic biomes (anthromes) characterize the human-altered form and dynamics of terrestrial ecosystems ${ }^{14}$. They denote long-term patterns in human populations and their land use, taking into account population density, agricultural village development, percent cover by crops, pasture and rice, irrigated land area and areas potentially covered by trees ${ }^{52,53}$. Anthromes version 2 data were calculated using a $100 \mathrm{~km}^{2}$ equal area hexagonal Discrete Global Grid format. For presentation, we grouped anthromes as either low intensity or high intensity to show differences in use between Indigenous Peoples' and other lands. Remote Rangelands, Remote Woodlands, Inhabited Treeless and Barren Lands, Wild Woodlands and Wild Treeless and Barren Lands anthromes were classified as low intensity; Urban, Dense Settlement, Rice Village, Irrigated Village, Rainfed Village, Pastoral Village, Residential Irrigated Croplands, Residential Rainfed Croplands and Populated Croplands were classified as high intensity. 


\section{Statistical analysis}

Regional variation in the proportion of countries in each region with Indigenous Peoples was tested with Chi-square with Fisher Exact test to test pairs, with $P$ values adjusted using the Bonferroni method. Comparisons of percentages of different land types under Indigenous Peoples' and other lands were undertaken using MannWhitney Wilcoxon test for countries with both land types. For countries with Indigenous Peoples, percentages of each land type in each region were compared using the Kruskal-Wallace test.

\section{Data availability}

The administrative areas data that support the findings of this study are available from Global Administrative Areas ${ }^{47}$. Data used for Indigenous Peoples' lands mapping are provided in the Extended Data Table 1 and the derived maps are available from author STG upon reasonable request. The protected areas data that support the findings of this study are available from the UN Environment's World Conservation Monitoring Centre ${ }^{13}$. The Human Footprint data that support the findings of this study are available in Dryad Digital Repository ${ }^{49}$. The anthromes version 2 data that support the findings of this study are available from author EE upon reasonable request. 


\section{References}

1. World Bank. Indigenous Peoples. http://www.worldbank.org/en/topic/indigenouspeoples (2017).

2. International Labour Organisation. C169 - Indigenous and Tribal Peoples Convention, 1989 (No. 169).

http://www.ilo.org/dyn/normlex/en/f?p=NORMLEXPUB:12100:0::NO::P12100_ILO_COD E:C169 (1989).

3. Berkes, F. Community-based conservation in a globalized world. Proc. Natl. Acad. Sci. U.S.A. $104,15188-15193(2007)$.

4. Sobrevila, C. The role of Indigenous peoples in biodiversity conservation (World Bank, Washington; 2008).

5. Gilbert, J. Indigenous Peoples' Land Rights under International Law (Brill, Leiden; 2016).

6. Stevens, S., Jaeger, T. \& Broome, N. P. ICCAs and Overlapping Protected Areas: Fostering Conservation Synergies and Social Reconciliation (ICC Consortium, Teheran; 2016).

7. Veit, P. \& Reytar, K. By the Numbers: Indigenous and Community Land Rights. http://www.wri.org/blog/2017/03/numbers-indigenous-and-community-land-rights (2017).

8. Bryan, J. Walking the line: participatory mapping, Indigenous rights, and neoliberalism. Geoforum 42, 40-50 (2011).

9. Gavin, M. C. et al. Defining biocultural approaches to conservation. Trends Ecol. Evol. 30, 140-145 (2015).

10. Forest Peoples Program, International Indigenous Forum on Biodiversity \& Secretariat of the Convention on Biological Diversity. Local Biodiversity Outlooks - Summary and Conclusions (Forest Peoples Programme, Moreton-in-Marsh; 2016).

11. Schmeller, D., Henle, K., Loyau, A., Besnard, A. \& Henry, P. Y. Bird-monitoring in Europe - a first overview of practices, motivations and aims. Nat. Cons. 2, 41-57 (2012). 
12. LandMark Global Platform of Indigenous and Community Lands http://www.landmarkmap.org/ 2018.

13. UNEP-WCMC and IUCN (2016), Protected Planet: The World Database on Protected Areas (UNEP-WCMC and IUCN, Cambridge; 2016).

14. Ellis, E. C. \& Ramankutty, N. Putting people in the map: anthropogenic biomes of the world. Front. Ecol. Environ. 6, 439-447 (2008).

15. Venter, O. et al. Global terrestrial Human Footprint maps for 1993 and 2009. Sci. Data 3, sdata201667 (2016).

16. Convention on Biological Diversity. Decision Adopted by the Conference of the Parties to the Convention on Biological Diversity at its Tenth Meeting X/2. The Strategic Plan for Biodiversity 2011 - 2020 and the Aichi Biodiversity Targets https://www.cbd.int/doc/decisions/cop-10/cop-10-dec-02-en.pdf (2010)

17. United Nations. Sustainable Development Goals. http://www.un.org/sustainabledevelopment (2015).

18. United Nations. Transforming Our World: 2030 Agenda for Sustainable Development. https://undocs.org/A/RES/70/1 (2015).

19. Díaz, S. et al. The IPBES Conceptual Framework-connecting nature and people. Curr. Opin. Environ. Sustain. 14, 1-16 (2015).

20. Renwick, A. R. et al. Mapping Indigenous land management for threatened species conservation: An Australian case-study. PloS One 12, e0173876 (2017).

21. Dowie, M. Conservation Refugees: the Hundred-Year Conflict between Global Conservation and Native Peoples (MIT press, London; 2011).

22. Watson, J. E. M. et al. Persistent disparities between recent rates of habitat conversion and protection and implications for future global conservation targets. Cons. Lett. 9, 413-421 (2016).

23. Watson, J. E. M. et al. Catastrophic declines in wilderness areas undermine global environment targets. Current Biol. 26, 2929-2934 (2016). 
24. Finer, M. et al. Future of oil and gas development in the western Amazon. Env. Res. Lett. 28, 024003 (2015).

25. Trosper, R. L. Northwest coast Indigenous institutions that supported resilience and sustainability. Ecol.Econ. 41, 329-344 (2002).

26. Simon, S., \& Randalls, S. Resilience and the politics of multiplicity. Dialog. Human Geog. 6, 45-49 (2016).

27. Norman, E. S. (2017). Standing up for inherent rights: The role of Indigenous-led activism in protecting sacred waters and ways of life. Soc. \& Nat. Res. 30, 537-553 (2017).

28. Brondizio, E.S. \& Le Tourneau, F-M. Environmental governance for all. Science 352, 1272-1273 (2016).

29. Mantyka-Pringle, C. S., Westman, C. N., Kythreotis, A. P. \& Schindler, D. W. Honouring Indigenous treaty rights for climate justice. Nat. Clim. Change 5, 798-801 (2015).

30. Corrigan, C. J. Robinson, C., Burgess, N. D., Kingston, N. \& Hockings, M. Global Review of Social Indicators used in Protected Area Management Evaluation. Cons. Lett. 11. doi:10.1111/conl.12397 (2017).

31. Kohler, F. \& Brondizio, E. S. Considering the needs of Indigenous and local populations in conservation programs. Conserv. Biol. 31, 245-251 (2017).

32. Tengö, M. et al. Weaving knowledge systems in IPBES, CBD and beyond-lessons learned for sustainability. Curr. Opin. Environ. Sustain. 26-27, 17-25 (2017).

33. Armitage, D., de Loë, R. \& Plummer, R. Environmental governance and its implications for conservation practice. Cons. Lett. 5, 245-255 (2012).

34. Convention on Biological Diversity. Akwé: Kon Voluntary Guidelines for the conduct of cultural, environmental and social impact assessment regarding developments proposed to take place on, or which are likely to impact on, sacred sites and on lands and waters traditionally occupied or used by Indigenous and local communities. Secretariat of the Convention on Biological Diversity, Montreal (2004). 
35. Convention on Biological Diversity. Revised draft of the elements of an ethical code of conduct to ensure respect for the cultural and intellectual heritage of Indigenous and local communities: Note by the Executive Secretary. UNEP/CBD/WG8J/6/4. Secretariat of the Convention on Biological Diversity, Montreal (2009).

36. Whakatane mechanism. http://whakatane-mechanism.org (2018).

37. Jonas $\mathrm{H}$. et al. Will OECMs increase recognition and support for ICCAs? PARKS 23, 2 (2017).

38. IUCN WCPA. Guidelines for Recognising and Reporting Other Effective Area-based Conservation Measures, Version 1 (IUCN, Gland; 2017).

39. Agnoletti, M. (Ed.). The conservation of cultural landscapes. CABI, Wallingford; 2006).

40. Wangpakapattanawong, P., Kavinchan, N., Vaidhayakarn, C., Schmidt-Vogt, D. \& Elliott, S. Fallow to forest: applying Indigenous and scientific knowledge of swidden cultivation to tropical forest restoration. For. Ecol. Management 260, 1399-1406 (2010).

41. Vigilante, T. et al. Collaborative research on the ecology and management of the 'Wulo' Monsoon Rainforest in Wunambal Gaambera Country, North Kimberley, Australia. Land 6, $68(2017)$.

42. Raymond, C.M. et al. Integrating local and scientific knowledge for environmental management. J.Env.Mgmt. 91,1766-1777 (2010).

43. Tengö, M., Brondizio, E. S., Elmqvist, T., Malmer, P. \& Spierenburg, M. Connecting diverse knowledge systems for enhanced ecosystem governance: the multiple evidence base approach. Ambio 43, 579-591 (2014).

44. Sangha, K.K. et al. An ecosystem services framework to evaluate Indigenous and local peoples' connections with nature. Ecosys. Serv. 31, 111-125 (2018).

45. Leiper, I. et al. Quantifying current and potential contributions of Australian Indigenous Peoples to threatened species management. Cons. Biol. (in press)

46. United Nations Department of Economic Affairs. State of the World's Indigenous Peoples, Vol. 9 (United Nations Publications, New York; 2009).

\section{References in Methods}


47. Global Administrative Areas (GADM) v2.8. Download. Global Administrative Areas http://gadm.org/version2 (2015).

48. Brooks, T. M. et al. Analysing biodiversity and conservation knowledge products to support regional environmental assessments. Sci. Data 3, 160007 (2016).

49. Venter O. et al. Data from: Global terrestrial Human Footprint maps for 1993 and 2009. Dryad Digital Repository. https://doi.org/10.5061/dryad.052q5.2 (2016).

50. Tucker M. A. et al. Moving in the Anthropocene: Global reductions in terrestrial mammalian movements. Science 359, 466-9.(2018).

51. Jones, K. R. et al. One-third of global protected land is under intense human pressure. Science 360, 788-791 (2018).

52. Ellis, E. C., Klein Goldewijk, K., Siebert, S., Lightman, D. \& Ramankutty, N. Anthropogenic transformation of the biomes, 1700 to 2000. Global Ecol. Biogeog. 19, 589-606 (2010).

53. Ellis, E. C. Anthropogenic transformation of the terrestrial biosphere. Phil. Trans. R. Soc. Lond. A: Math. Phys. Eng. Sci. 369, 1010-1035 (2011).

Supplementary Information is available in the online version of the paper. Online content Methods, along with any Extended Data display items and Source Data, are available in the online version of the paper; references unique to these sections appear only in the online paper.

Acknowledgements We thank the thousands of people and government agencies who contribute to the World Database on Protected Areas (WDPA) that is jointly developed by UN Environment and IUCN and managed by UNEP-WCMC in Cambridge, UK. We would also like to acknowledge the efforts of those involved in participatory mapping of Indigenous lands, particularly Fabrice Dubretet and others involved in developing the LandMark global platform for Indigenous and Community 
Lands. Early advice on the research was provided by Alejandro Parellada, Lola García-Alix and Geneviève Rose of the International Work Group for Indigenous Affairs and contributors to the World Parks Congress 2014 symposium on Contributions to biodiversity conservation by the Indigenous Peoples and Local Communities of Africa: Valerie Courtois, Hmalan Hunter-Xenie, Ashish Kothari, Joe Morrison, Gustavo Oviedo, John Scott, Bev Sithole, Alifereti Tawake and Leonard Usongo. Additional national advice was kindly provided by Rémi Andreoli (New Caledonia), Jayson Ibanez (Philippines), Neil Aldrin Mallari (Philippines), Julie Scopélitis (New Caledonia), Eloise Stancioff (Dominica), Veronica Toral-Grande (Ecuador) and Miguel Tovar-Valencia (Mexico). Jerry Harrison and Heather Bingham provided helpful comments on the final manuscript and Linda Luck helped with illustrations.

Author contributions STG conceived of the paper, drafted the initial text and analysed data. STG, TD, MVJ, BM, AS and IL located the maps and IL undertook the GIS analysis. JEF, KKZ, IL and HG analysed data. All 20 authors contributed ideas and finalised the text.

Author information The authors declare no financial or non-financial competing interests. Correspondence and requests for materials should be addressed to STG. (stephen.garnett@cdu.edu.au). 


\section{Figure captions}

Fig. 1. Global map of lands managed and/or controlled by Indigenous Peoples (percent of each degree square mapped as Indigenous in at least one of 127 source documents, Extended Data Table 1). Blank areas do not necessarily indicate an absence of Indigenous Peoples or their lands, but rather areas for which an Indigenous connection cannot be inferred based on publicly available geospatial data. Note that the equal area Mollweide projection adopted gives appropriate weight to tropical regions where most Indigenous Peoples have land but at the expense of accuracy in shape which can make it difficult to determine Indigenous lands in some countries on the margins of the map, such as New Zealand (see Supplementary Table 2).

Fig. 2. a. Intersections among Indigenous lands, protected areas and natural landscapes globally and for each IPBES Region. Circles and intersections are all proportional to area with the largest circle scaled to the land area of the earth (135.2 million km² excluding Antarctica). b. Comparisons between Indigenous Peoples' lands and other lands for protected areas, natural areas (Human Footprint score <4), low intensity anthropogenic biomes (anthromes) and high intensity anthromes. Significance assessed with Mann Whitney Wilcoxon test for countries with land in both categories ( $n=84$ ); box contains $50 \%$ records, bar is median percentage; Extended Data Table 3). 
Fig. 3. Area of each anthropogenic biome $\left(\right.$ anthrome $\left.^{14}\right)$ on Indigenous Peoples' land (brown) compared to other lands (yellow). Intensity of land use on each anthrome declines from top to bottom.

Fig. 4. National percentages of Indigenous Peoples' and other lands in protected areas $^{13}$, with a Human Footprint score $<4^{22}$ and in low and high intensity anthromes ${ }^{14}$ as well as the percentage of each land type that is mapped as either Indigenous Peoples' or other. 


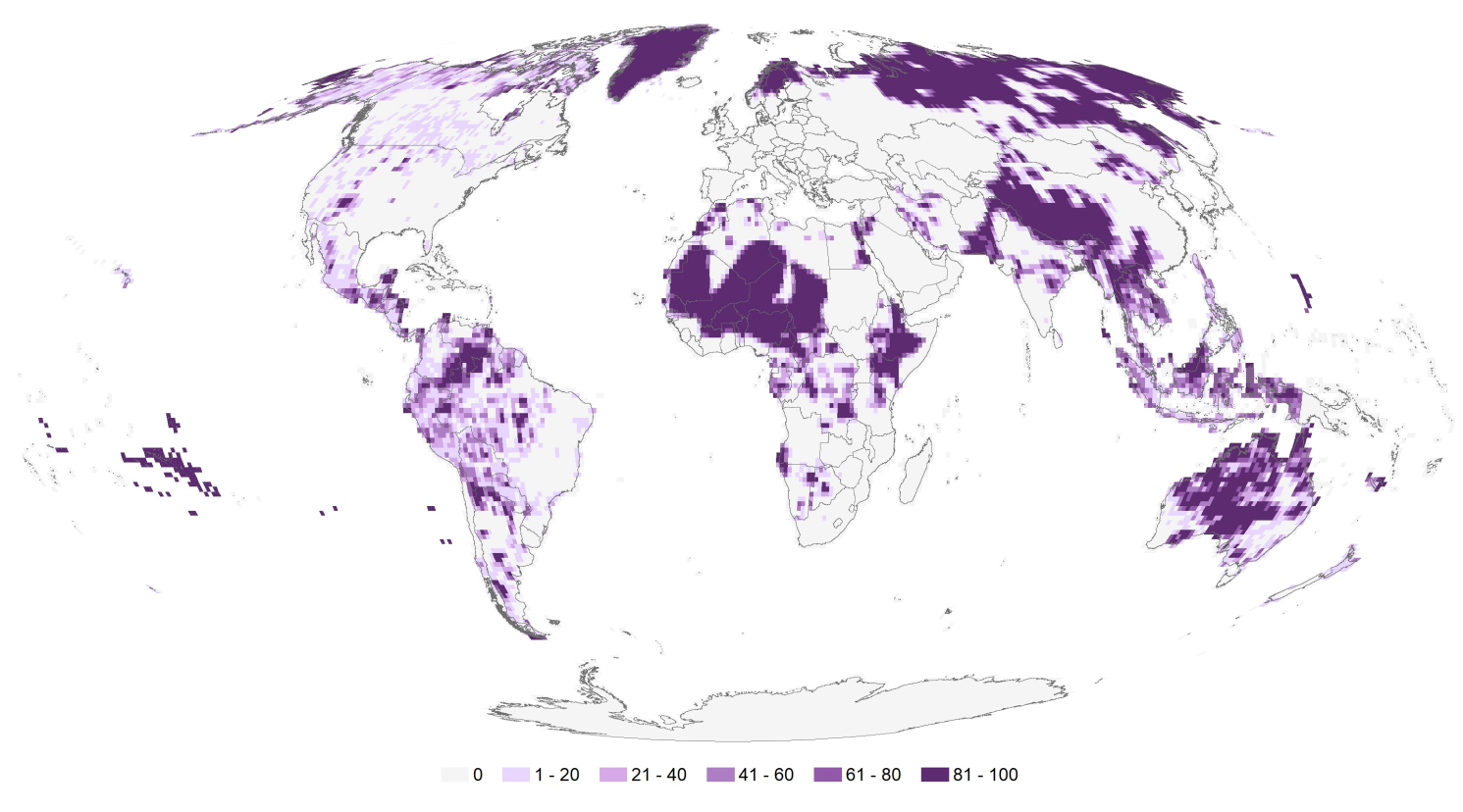




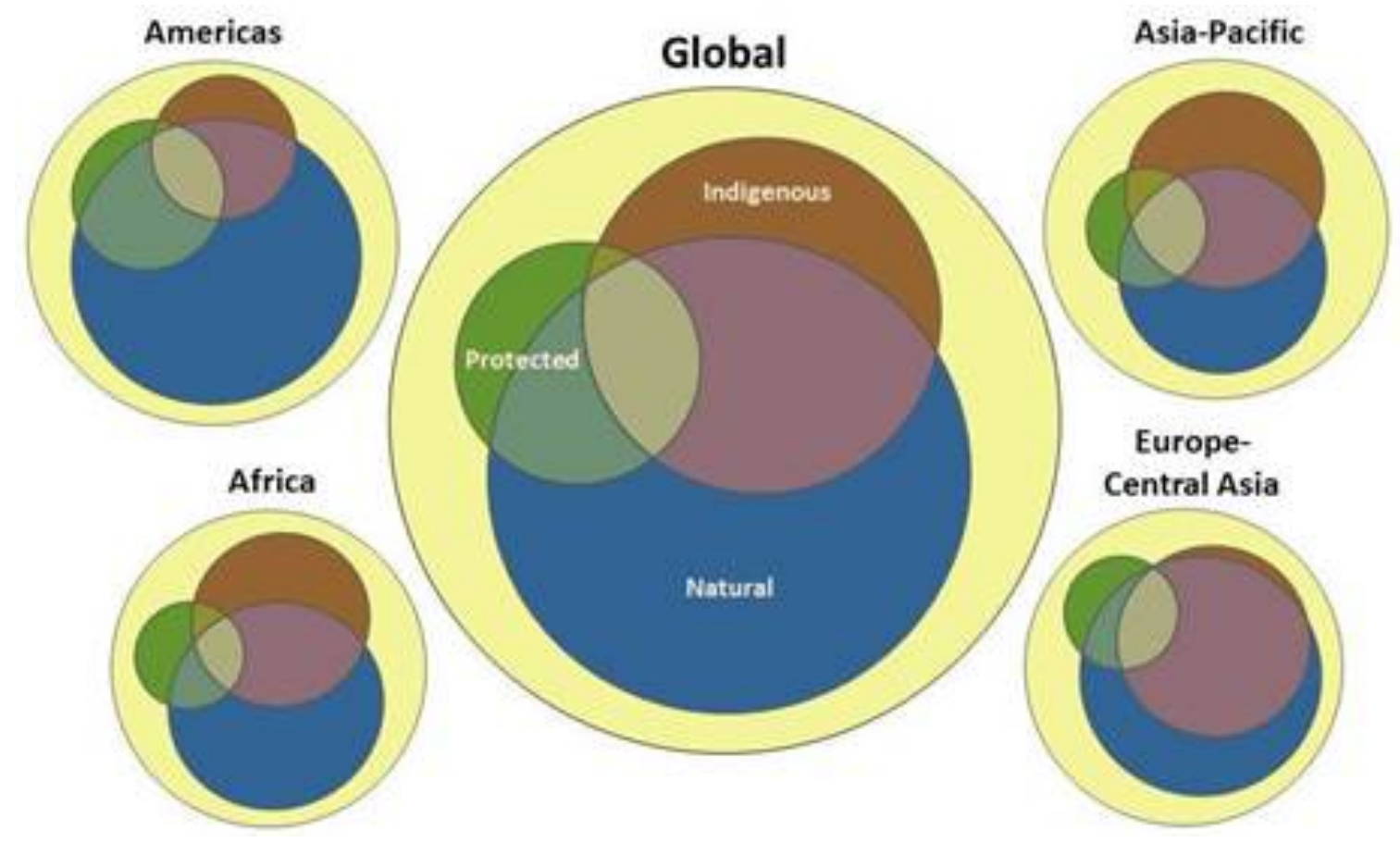



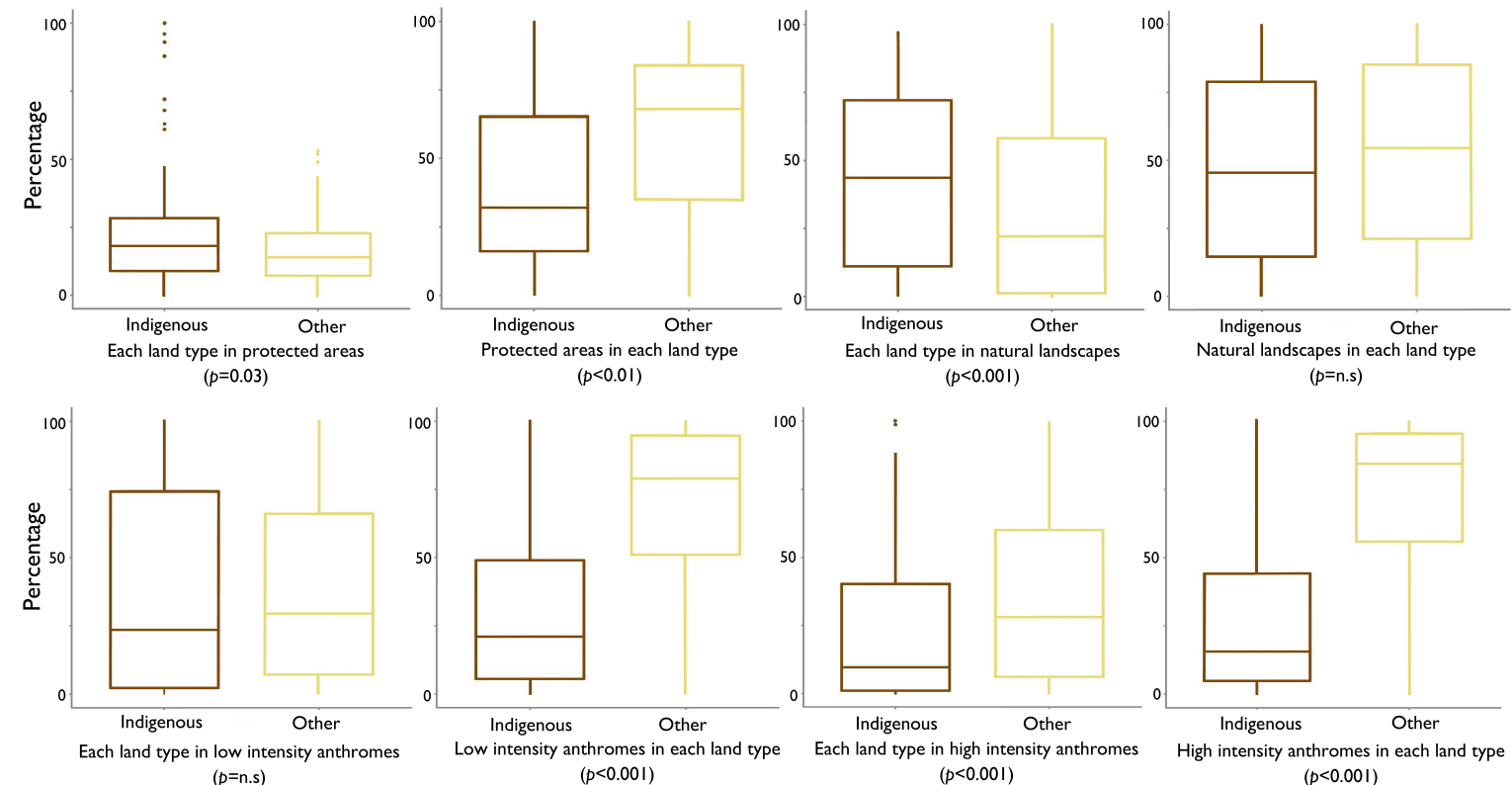
( $p=n . s)$ $(p<0.001)$ $(p<0.00 \mathrm{I})$ $(p<0.00 \mathrm{I})$ 


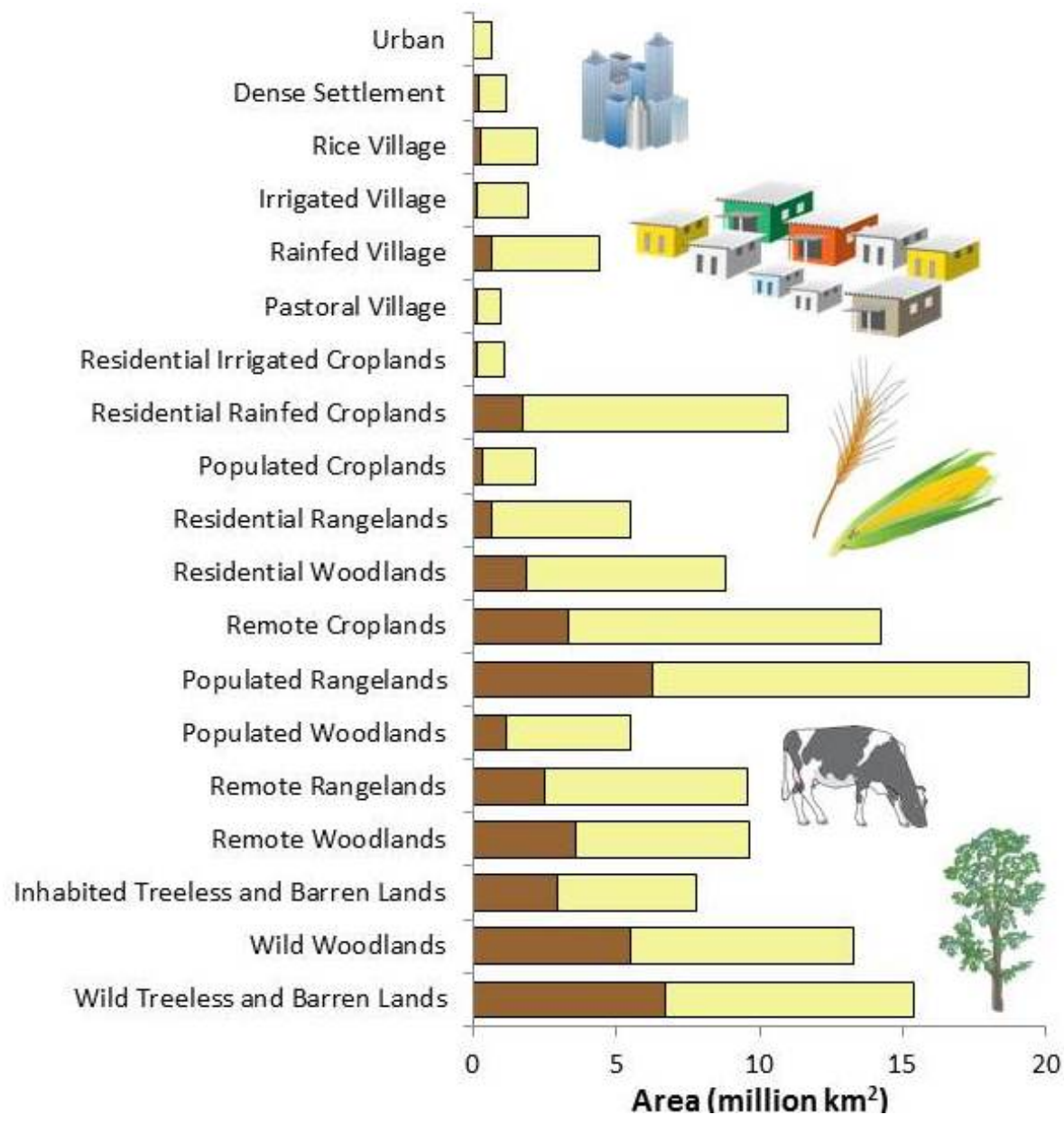




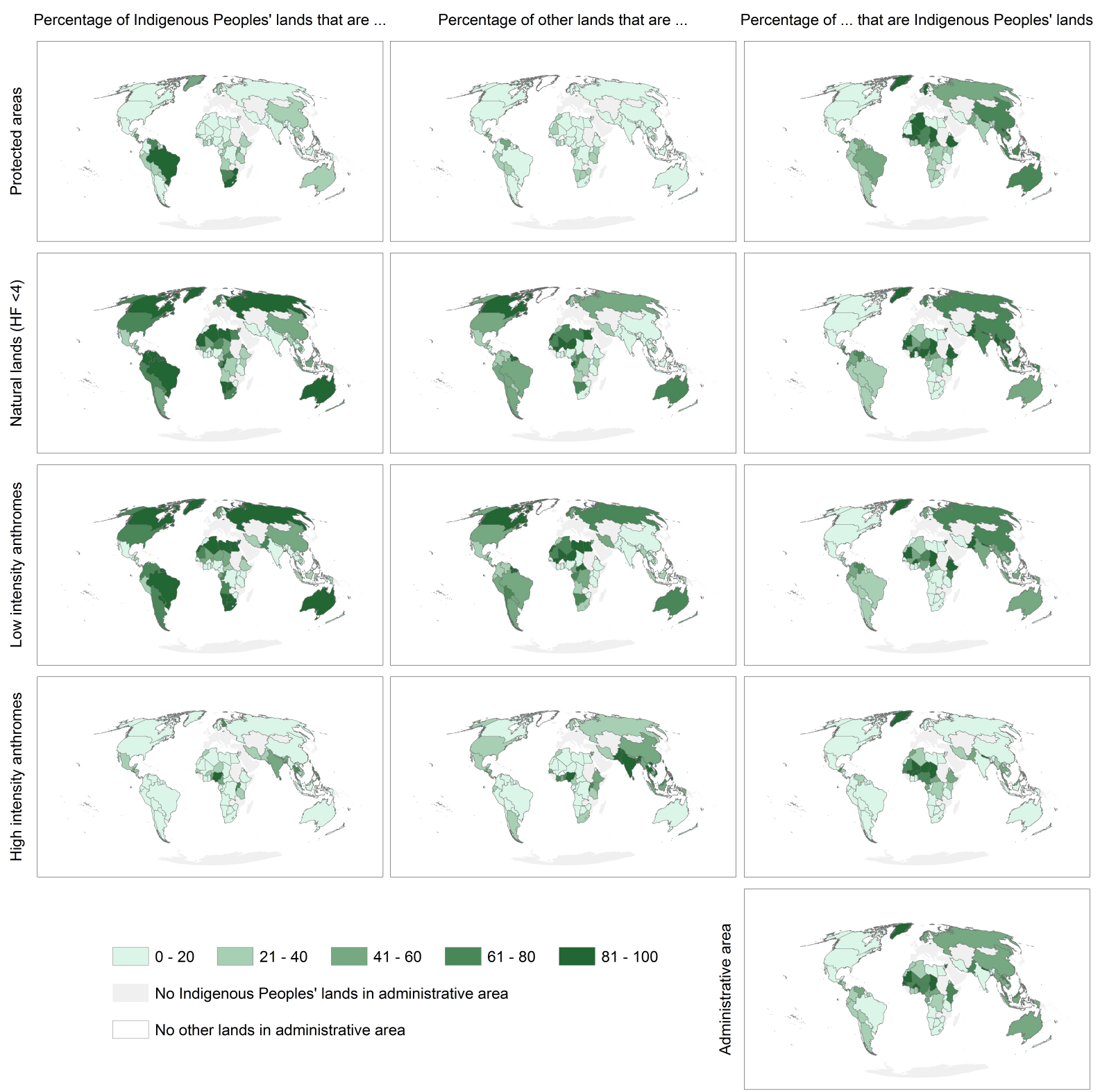

